
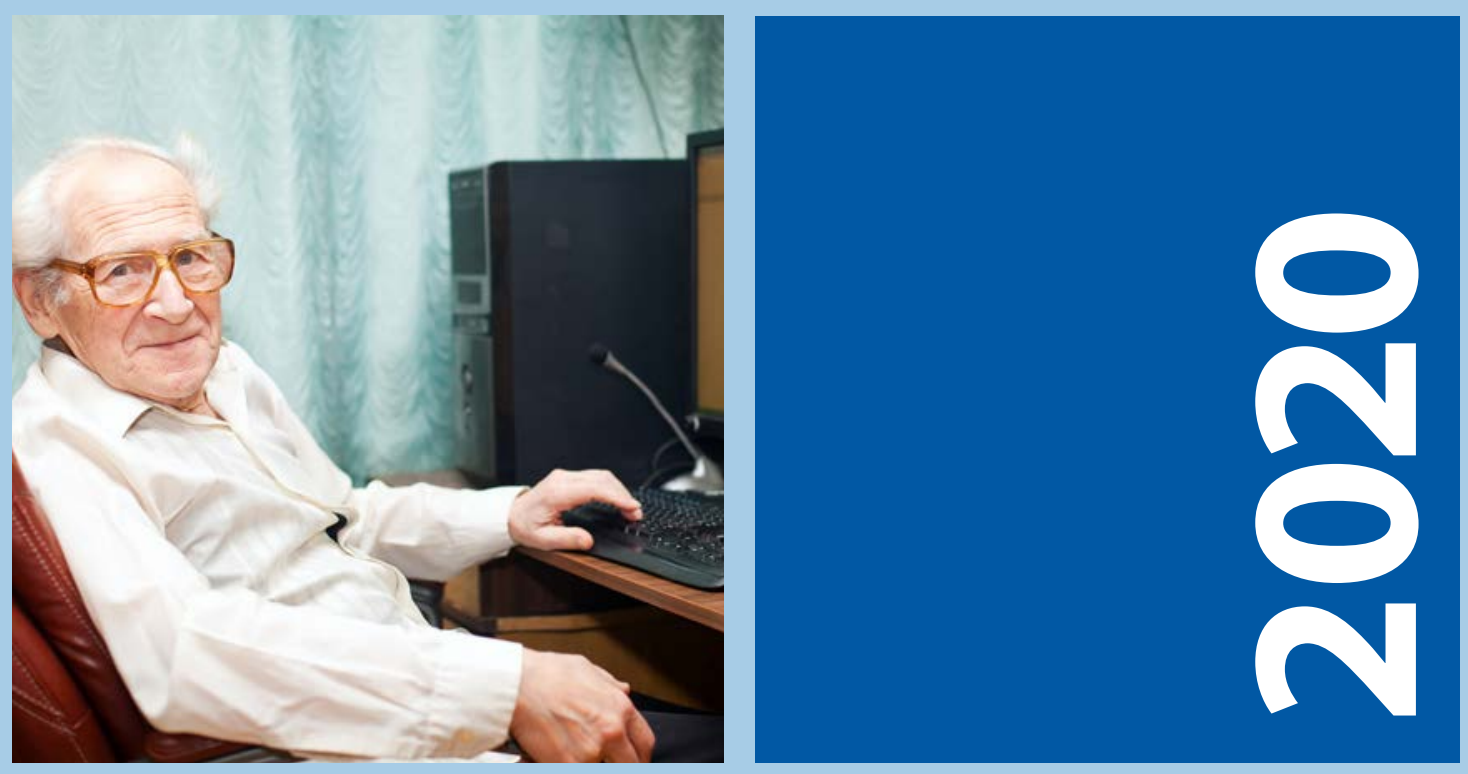

Internet access and use among adults aged 50 and over in Ireland: Results from Wave 5 of The Irish Longitudinal Study on Ageing

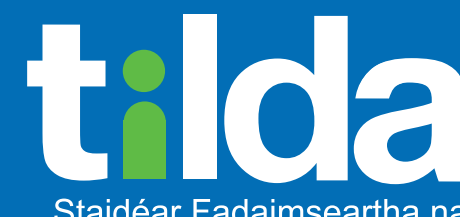

Staidéar Fadaimseartha na hÉireann um Dhul in Aois

The Irish Longitudinal Study on Ageing 


\section{Internet access and use among adults aged 50 and over in Ireland: Results from Wave 5 of The Irish Longitudinal Study on Ageing}

Paul Doody, Minjuan Wang, Siobhan Scarlett, Ann Hever,

Paul O'Mahoney and Rose Anne Kenny

The Irish Longitudinal Study on Ageing

On behalf of the TILDA team

May 2020 
Copyright (c) The Irish Longitudinal Study on Ageing 2020

The Irish Longitudinal Study on Ageing

Trinity College Dublin

Dublin 2

Tel: +35318962509

Email: tilda@tcd.ie

Website: www.tilda.ie

ISBN: 978-1-907894-31-2

https://www.doi.org/10.38018/TildaRe.2020-06 


\section{Acknowledgements}

We would like to acknowledge the vision and commitment of our study funders, the Department of Health, the Health Research Board, Science Foundation Ireland, The Atlantic Philanthropies, and Irish Life plc. We would like to state that any views expressed in this report are not necessarily those of the Department of Health or of the Minister for Health. We would also like to thank the TILDA participants without whom this research would not be possible. 


\section{Contents}

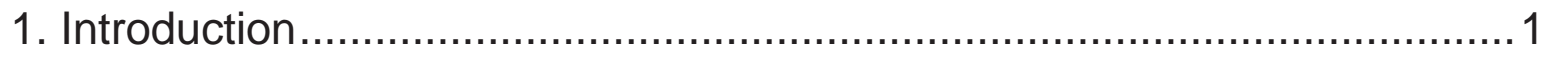

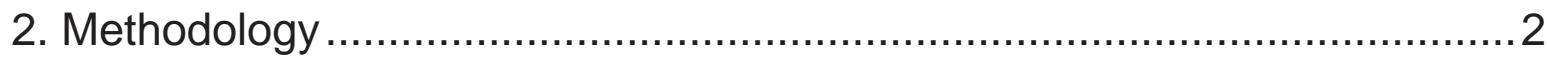

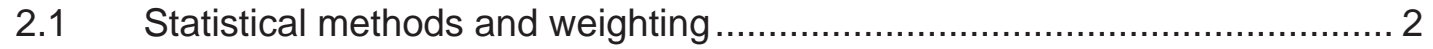

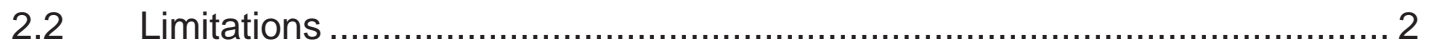

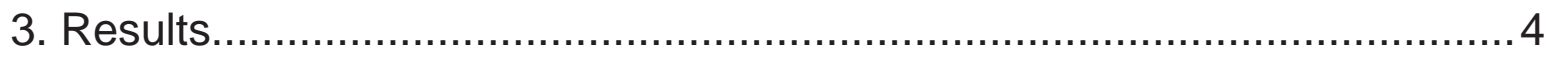

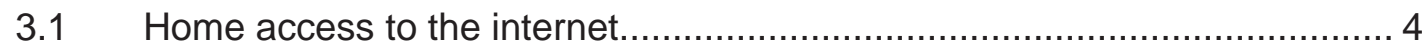

3.2 Smartphone/tablet access, and access to apps.................................... 5

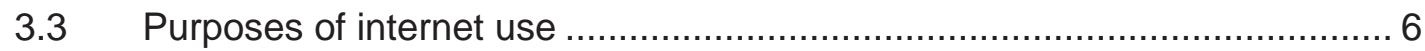

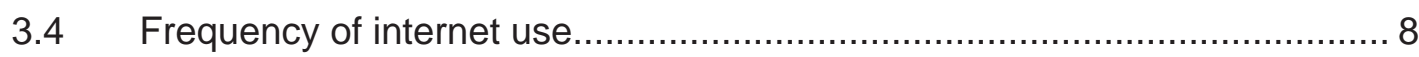

3.5 Reliance on internet access external to home ..................................... 10

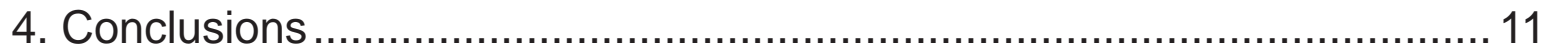

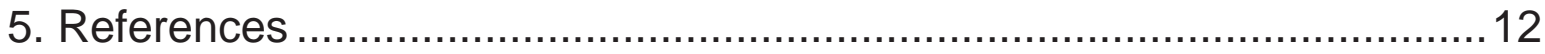




\section{Internet access and use}

\section{among adults aged \\ $50+$ in Ireland}

\section{Common Purposes of Internet Use}

$\begin{aligned} & \text { Searching for } \\ & \text { Information } \\ & 810,000\end{aligned}$
$\begin{aligned} & \text { Sending \& } \\ & \text { Receiving } \\ & \text { Emails } \\ & 740,000\end{aligned}$
$\begin{aligned} & 72 \% \\ & \text { Payments } \\ & 600,000\end{aligned}$
$\begin{aligned} & \text { Accessing } \\ & \text { News } \\ & 585,000\end{aligned}$
$\begin{aligned} & \text { Audio \& } \\ & \text { Video Calls }\end{aligned}$

$1,000,000 \quad 71 \% \quad$ adults aged $50+$ have access to the internet in their homes.

900,000

870,000

$700,000 \quad 68 \%$ adults aged 50 + have access to smartphones/tablets (and so to apps).

adults with home internet access use the internet weekly.

adults with home internet access use the internet daily.

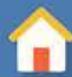

Home internet access

decreases with age:
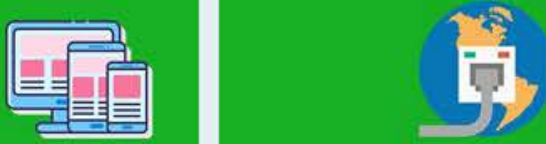

$\mathbf{8 6 \%}$ aged $50-69$ years; $66 \%$ aged $70-79$ years; $38 \%$ aged $80+$ years.

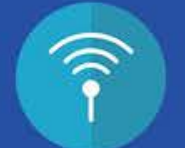

$3 \%$ OF ADULTS AGED 50+ RELY ON ACCESSING INTERNET

THROUGH FRIENDS, RELATIVES, HOME, LIBRARY,

COMMUNITY CENTRES AND PUBLIC WI-FI NETWORKS.

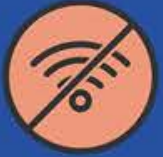

$30 \%$ OF ADULTS AGED 50+, AND WHO ARE LIVING ALONE, DO NOT HAVE INTERNET ACCESS IN THEIR HOMES.

For more information please visit www.tilda.ie Supported by $\mid \begin{aligned} & \text { An Roinn Slainte } \\ & \text { Department of Health }\end{aligned} \mathbf{R}^{\mathbf{B}} \begin{aligned} & \text { Health } \\ & \text { Research } \\ & \text { Board }\end{aligned}$ 


\section{Key Findings}

- $71 \%$ of adults aged $\mathbf{5 0 +}$ have access to the internet in their homes (approximately 1 million adults).

- Internet access decreases with age. Only $38 \%$ aged $80+$ have home internet access, compared to $86 \%$ aged $50-69$ years, and 66\% aged $70-79$ years.

- $74 \%$ aged $50+$ in urban areas have home internet access; $67 \%$ in rural areas.

- $64 \%$ of adults aged $50+$ have access to a smartphone/tablet (and therefore to apps) (approximately 900,000).

- Access to smartphones/tablets similarly decreases with age. Only $30 \%$ aged $80+$ have access to a smartphone/tablet, compared to $80 \%$ aged $50-69$ years, and $60 \%$ aged $70-79$ years.

- Common internet uses among those aged 50+ include:

- $\quad$ Searching for information: $79 \%(810,000)$

- Sending and receiving emails: $72 \%(740,000)$

- Financial transactions: $58 \%(600,000)$

- News: $57 \%(585,000)$

- Audio/video calls: $43 \%(440,000)$

- Social media: $40 \%(410,000)$

- $\quad$ Gaming/apps: $17 \%(175,000)$

- Internet use for any purpose declines with increased age, with social media use experiencing the largest of these age-associated declines from $47 \%$ in those aged 50 69 years, $30 \%$ aged $70-79$ years, to only $20 \%$ aged $80+$.

- Women use social media more than men, with $46 \%$ of women aged $50+$ using the internet for this purpose, compared to $33 \%$ of men.

- $\mathbf{6 8 \%}$ of adults aged $\mathbf{5 0 +}$ use the internet daily (approximately 700,000 ); $\mathbf{8 5 \%}$ weekly (approximately 870,000).

- $3 \%$ of adults aged $50+$ use the internet but are solely reliant on internet access external to their homes (approximately 40,000) e.g. friends'/relatives' home, library, community centre and public Wi-Fi networks.

- Of adults aged 50+ living alone, $30 \%$ do not have internet access in their homes. 


\section{Introduction}

This report will outline internet access and use among adults aged 50 years and over in Ireland. These analyses are based on data from wave 5 of the Irish Longitudinal Study on Ageing (TILDA), collected in 2018. These analyses have been conducted presently in the context of the Coronavirus Disease-2019 (COVID-19) pandemic, when access to the internet has become increasingly important to many people in their working and personal lives. It is the latest in a series of reports produced by TILDA, aimed at helping the response to, and understanding of the pandemic in Ireland (1-6).

Public health measures introduced by the Irish government in response to the COVID-19 pandemic have included social distancing, and encouragement of older adults and those with underlying health conditions to stay at home and abstain from contact with others, except in exceptional circumstances $(7,8)$. A recently published TILDA report outlining the incidence of loneliness among those aged 50 years and over in Ireland, shows 7\% experience emotional loneliness on a frequent basis, and almost one in three experience emotional loneliness at least some of the time (9). It is likely the introduction of social distancing and self-isolation measures will exacerbate loneliness, given that one of the commonest causes of loneliness is social isolation. Internet use offers an effective method of alleviating some of the negative consequences of these measures by enabling virtual interactions (10). Moreover, the use of internet by institutions and organisations as a platform for information distribution, access to support services and the continuation of commerce during the COVID-19 pandemic has increased substantially (11-14).

In this context, this report will outline internet access and use among adults aged 50 years and over in Ireland, using population estimates derived from data collected during Wave 5 of TILDA in 2018, in conjunction with the most recent 2016 Census data. Specifically, information will be provided regarding home access to the internet; access to smartphones/tablets (ergo access to apps); and the frequency and purpose of internet use. This report will also provide information regarding those who are solely reliant on internet access external to their own homes, as well as the lack of internet access among those living alone. 


\section{Methodology}

\subsection{Statistical methods and weighting}

All estimates are based on data from the most recent wave of TILDA in 2018 (Wave 5), which included data from 5,206 participants. All prevalence estimates are weighted to account for age, sex, educational attainment, and urban/rural residence in the 2016 Census, as well as the probability that participants returned a completed Self-Completion Questionnaire (SCQ) during Wave 5 of TILDA. This ensures that estimates are closely representative of the entire population aged 50 years and over in Ireland. Population estimates are based on information from the most recent Census data (2016), which reported a total of 1,446,460 people aged 50 years and over living in Ireland.

\section{$2.2 \quad$ Limitations}

Differences in the age group and sex distribution between participants in Wave 5 of TILDA and the 2016 Census (Table 1) mean there will be minor rounding errors with regard to the estimated age group and sex breakdowns throughout the report. This is due to applying the weighted prevalence to the overall population and further stratifying by age group and sex. As a result, in some cases these numbers will not match precisely those derived for the total population estimate. Furthermore, as the TILDA cohort was initially recruited from, and still comprises predominantly of, community-dwelling older adults, there are limitations to the external validity of these findings regarding extrapolation of weighted prevalence to the entire population ages $50+$ to derive overall population estimates. 
Table 1. Sex and age group distribution of Wave 5 of TILDA, and the 2016 Irish Census

\begin{tabular}{|l|c|c|}
\hline Age group / Sex & TILDA participants (\%) & 2016 Census (\%) \\
\hline $50-69$ years & $2,648(52)$ & $1,020,129(71)$ \\
\hline Male & $1,109(22)$ & $505,729(35)$ \\
\hline Female & $1,539(30)$ & $514,440(36)$ \\
\hline $70-79$ years & $1,614(32)$ & $277,739(19)$ \\
\hline Male & $747(15)$ & $133,618(9)$ \\
\hline Female & $867(17)$ & $144,121(10)$ \\
\hline $80+$ years & $825(16)$ & $148,592(10)$ \\
\hline Male & $366(7)$ & $58,258(4)$ \\
\hline Female & $459(9)$ & $90,334(6)$ \\
\hline
\end{tabular}




\section{Results}

\subsection{Home access to the internet}

Approximately 1 million adults aged 50+ in Ireland (71\%) have access to the internet in their homes. The prevalence of home internet access decreases with age, from $86 \%$ aged 50-69 years, to $66 \%$ aged $70-79$ years, and $38 \%$ aged $80+$.

The overall prevalence of home internet access is relatively evenly distributed when stratified by sex, with just over $70 \%$ of men and women having access to the internet in their homes. However, the relative prevalence of home internet access when stratified by sex changes with age; approximately 10\% more women aged 50-69 years have home access to the internet compared to men, while among those aged $80+$ this sex difference is reversed, with approximately $25 \%$ more men having home access to the internet compared to women (Table 2). Additionally, there is a minor urban/rural divide, with $74 \%$ aged $50+$ living in urban areas having home access to the internet, compared to $67 \%$ in rural areas.

Table 2. Home access to the internet, stratified by age group and sex, amongst adults aged 50 years and over in Ireland

\begin{tabular}{|l|c|c|c|}
\hline Age group / Sex & $\begin{array}{c}\text { Total population } \\
(\mathbf{n})\end{array}$ & $\begin{array}{c}\text { Home access to } \\
\text { the internet* } \\
\mathbf{( \% )}\end{array}$ & $\begin{array}{c}\text { Home access to } \\
\text { the internet } \\
(\mathbf{n})\end{array}$ \\
\hline Total (50+ years) & $1,446,460$ & 71.1 & $1,028,374$ \\
\hline Male & 697,605 & 71.5 & 498,617 \\
\hline Female & 748,855 & 70.7 & 529,707 \\
\hline $50-69$ years & $1,020,129$ & 86.0 & 876,920 \\
\hline Male & 505,729 & 82.6 & 417,509 \\
\hline Female & 514,400 & 89.5 & 460,244 \\
\hline $70-79$ years & 277,739 & 66.3 & 184,131 \\
\hline Male & 133,618 & 66.7 & 89,186 \\
\hline Female & 144,121 & 65.9 & 94,923 \\
\hline $80+$ years & 148,592 & 37.8 & 56,237 \\
\hline Male & 58,258 & 43.9 & 25,581 \\
\hline Female & 90,334 & 33.4 & 30,153 \\
\hline
\end{tabular}




\subsection{Smartphone/tablet access, and access to apps}

Over 900,000 adults aged 50+ in Ireland (64\%) have access to a smartphone/tablet, and ergo access to apps. The prevalence of access to these devices decreases with age, from almost $80 \%$ of those aged $50-69$ years, $59 \%$ aged $70-79$, and falling to $30 \%$ aged $80+$.

The overall prevalence of smartphone/tablet access is relatively evenly distributed when stratified by sex, with slightly under $66 \%$ of men and women aged $50+$ having access to these devices (Table 3).

Table 3. Access to smartphones/tablets, stratified by age group and sex, amongst adults aged 50 years and over in Ireland.

\begin{tabular}{|l|c|c|c|}
\hline Age group / Sex & $\begin{array}{c}\text { Total population } \\
(\mathbf{n})\end{array}$ & $\begin{array}{c}\text { Access to } \\
\text { smartphones/ } \\
\text { tablets }(\%)\end{array}$ & $\begin{array}{c}\text { Access to } \\
\text { smartphonel } \\
\text { tablets (n) }\end{array}$ \\
\hline Total (50+ years) & $1,446,460$ & 64.2 & 928,910 \\
\hline Male & 697,605 & 62.8 & 438,247 \\
\hline Female & 748,855 & 65.5 & 490,848 \\
\hline 50-69 years & $1,020,129$ & 79.7 & 813,309 \\
\hline Male & 505,729 & 75.2 & 380,431 \\
\hline Female & 514,400 & 84.4 & 433,978 \\
\hline $70-79$ years & 277,739 & 58.9 & 163,677 \\
\hline Male & 133,618 & 56.9 & 76,029 \\
\hline Female & 144,121 & 60.9 & 87,746 \\
\hline $80+$ years & 148,592 & 30.0 & 44,627 \\
\hline Male & 58,258 & 33.2 & 19,370 \\
\hline Female & 90,334 & 27.7 & 24,991 \\
\hline
\end{tabular}




\subsection{Purposes of internet use}

Participants were asked to report the type of activities they use the internet for (Table 4). The list of activities shows among adults aged 50+ who have access to the internet in their homes, searching for information (79\%) and sending/receiving e-mails (72\%) are the most common activities, while just $17 \%$ use the internet for gaming/apps.

Common internet uses among those aged 50+ with home internet access include:

- Searching for information: $79 \%(810,000)$

- Sending and receiving emails: $72 \%(740,000)$

- Financial transactions: $58 \%(600,000)$

- News: $57 \%(585,000)$

- Audio/video calls: $43 \%(440,000)$

- Social media: $40 \%(410,000)$

- Gaming/apps: $17 \%(175,000)$

Women report higher internet use for sending/receiving emails, participating in audio/video calls, accessing social media, and gaming/apps than men. Men report higher internet use for information searching, conducting financial transactions, and accessing news sites. While there are relatively minor differences between sexes in most of these categories, women report much higher use of social media, with $46 \%$ of women aged $50+$ accessing social media compared to $33 \%$ of men.

Internet use for all purposes decline with increased age, with the largest of these ageassociated declines observed in the use of social media, and online financial transactions, both of which decline by more than half in those aged 50-69 years, compared to those aged $80+$, from $47 \%$ to $20 \%$, and $66 \%$ to $31 \%$ respectively. 


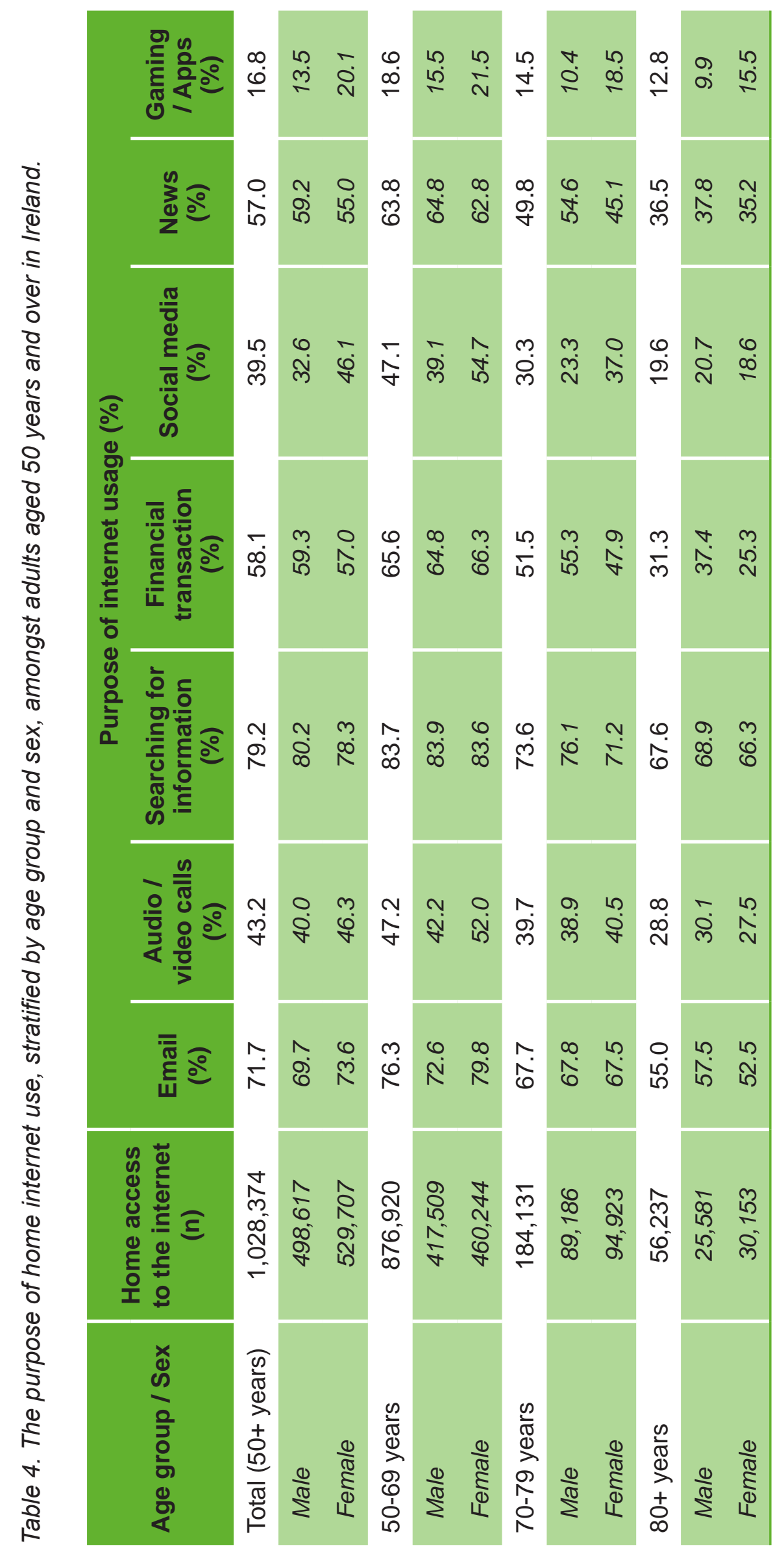




\subsection{Frequency of internet use}

Of the over 1 million adults aged 50+ who have home internet access, approximately $700,000(68 \%)$ use the internet every day or almost every day, while approximately $870,000(85 \%)$ use the internet at least once per week. The frequency of internet use declines with age, with over 75\% aged 50-69 years using the internet daily, compared to $59 \%$ aged $70-79$ years, and $44 \%$ aged $80+$. This difference is reduced in figures for weekly use, with approximately $90 \%$ aged $50-69$ years, $80 \%$ aged $70-79$ years, and $70 \%$ aged $80+$ using the internet at least once a week (Table 5). 


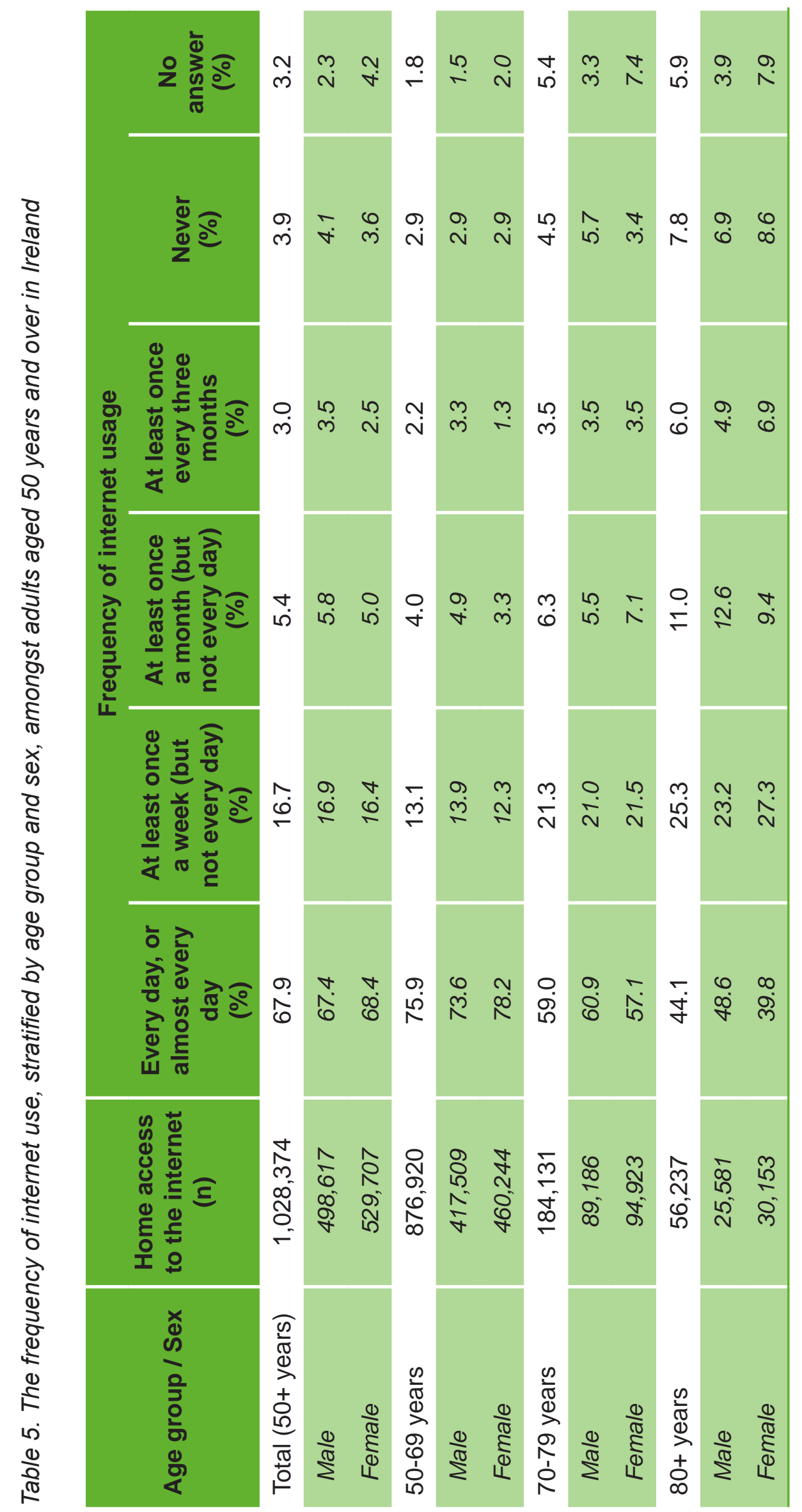




\subsection{Reliance on internet access external to home}

Over 40,000 adults aged 50+ in Ireland (3\%) use the internet but have no access within their own homes. These individuals have indicated a sole reliance on external sources of internet access, e.g. friends'/relatives' home, library, community centre and public Wi-Fi networks. The present unavailability of many of these external sources of internet access, owing to the measures implemented to combat COVID-19, means these individuals may be particularly negatively impacted, with important resources for communication and commerce available to them only a number of weeks ago presently unavailable (Table 6). Furthermore, of those aged 50+ living alone in Ireland, 30\% are without home access to the internet. These individuals also represent a relatively large cohort of the population who are potentially more vulnerable to social isolation and loneliness during present restrictions.

Table 6. Reliance on external sources of internet access, stratified by age group and sex, amongst adults aged 50 years and over in Ireland

\begin{tabular}{|l|c|c|c|}
\hline Age group / Sex & $\begin{array}{c}\text { Total population } \\
(\mathbf{n})\end{array}$ & $\begin{array}{c}\text { Reliant on external } \\
\text { internal access (\%) }\end{array}$ & $\begin{array}{c}\text { Reliant on external } \\
\text { internet access (n) }\end{array}$ \\
\hline Total (50+ years) & $1,446,460$ & 3.0 & 42,687 \\
\hline Male & 697,605 & 3.2 & 22,481 \\
\hline Female & 748,855 & 2.7 & 20,170 \\
\hline 50-69 years & $1,020,129$ & 2.9 & 8,455 \\
\hline Male & 505,729 & 3.2 & 5,045 \\
\hline Female & 514,400 & 2.7 & 3,375 \\
\hline $70-79$ years & 277,739 & 3.0 & 4,148 \\
\hline Male & 133,618 & 3.8 & 1,276 \\
\hline Female & 144,121 & 2.3 & 2,921 \\
\hline $80+$ years & 148,592 & 2.8 & 8,455 \\
\hline Male & 58,258 & 2.2 & 5,045 \\
\hline Female & 90,334 & 3.2 & 3,375 \\
\hline
\end{tabular}




\section{Conclusions}

Among adults aged 50 years and over in Ireland, there is a high access to the internet with frequent and varied use. The internet provides a valuable resource to maintain social interactions, obtain information, access support services and conduct everyday commerce during the COVID-19 pandemic. Access to apps via smartphone/tablets will be important in light of plans for optional contact tracing apps.

There is, however, a relatively large section of the population aged 50 years and over who do not have home internet access. This is particularly the case for older adults. This cohort of adults may be particularly at risk of loneliness as a result of restrictions and social isolation, and have a reduced capacity to access information, support services, and online commerce during the COVID-19 pandemic. For these individuals, and in particular those living alone and older age groups, more traditional forms of communication and information distribution, e.g. telephone, radio, television, and the national postal service, in combination with ongoing family and community support, are likely essential. 


\section{References}

1. Roe L, McGarrigle C, Hernández B, O'Halloran A, Scarlett S, Ward M, et al. Patterns in healthcare utilisation: results from wave 5 of the Irish longitudinal study on ageing. April 2020. DOI: https://www.doi.org/10.38018/TildaRe.2020-04. Accessed 15th May 2020.

2. Hernández B, Sexton D, Moriarty F, Cosgrave N, O'Halloran A, McGarrigle C, et al. High-risk categories for COVID-19 and their distribution by county in Republic of Ireland - evidence from the TILDA study. April 2020 DOI: https://www.doi.org/10.38018/ TildaRe.2020-03. Accessed 15th May 2020.

3. O'Halloran A, McGarrigle C, Scarlett S, Roe L, Romero-Ortuno R, Kenny RA. TILDA report on population estimates of physical frailty in Ireland to inform demographics for over 50s in Ireland during the COVID-19 pandemic. April 2020 DOI: https://www.doi. org/10.38018/TildaRe.2020-02. Accessed 15th May 2020.

4. Laird E, Kenny RA. Vitamin D deficiency in Ireland - Implications for COVID-19. Results from the Irish longitudinal study on ageing. April 2020 DOI: https://www.doi. org/10.38018/TildaRe.2020-05. Accessed 15th May 2020.

5. McGarrigle C, Ward M, Scarlett S, Kenny RA. The contributions of the over 70s to Irish society: results from wave 5 of the Irish longitudinal study on ageing. March 2020. DOI: https://www.doi.org/10.38018/TildaRe.2020-01. Accessed 15th May 2020.

6. Kenny RA, Hernández B, O'Halloran A, Moriarty F, McGarrigle C. TILDA report to inform demographics for 50s in Ireland for COVID-19 crisis. March 2020. DOI: https:// www.doi.org/10.38018/TildaRe.2020-00. Accessed 15th May 2020.

7. Health Service Executive (HSE), Ireland. Guidance on cocooning to protect people over 70 years and those extremely medically vulnerable from COVID-19. URL: https://www.hpsc.ie/a-z/respiratory/coronavirus/novelcoronavirus/guidance/ vulnerablegroupsguidance/COVID-19\%20Guidance $\% 20$ for $\% 20$ extremely $\% 20$ medically\%20vulnerable\%20V1.pdf. 27th March 2020. Accessed 15th May 2020. 
8. Department of Health Ireland. Guidance on cocooning to protect people over 70 years and those extremely medically vulnerable from COVID-19. URL: https://www.gov.ie/ en/publication/923825-guidance-on-cocooning-to-protect-people-over-70-years-andthose-extrl. 27th March 2020. Accessed 15th May 2020.

9. Ward M, Layte R, Kenny RA. Loneliness, social isolation, and their discordance among older adults. Findings from the Irish longitudinal study on ageing (TILDA). October 2019. DOI: https://www.doi.org/10.38018/TildaRe.2019-03. Accessed 15th May 2020.

10. Khosravi P, Rezvani A, Wiewiora A. The impact of technology on older adults' social isolation. Comput Hum Behav 2016;63:594-603.

11. Department of Health (Ireland). COVID-19 (Coronavirus). 2020; Available at: https:// www.gov.ie/en/campaigns/c36c85-covid-19-coronavirus/. Accessed 15th May, 2020.

12. Health Service Executive (Ireland). Coronavirus (COVID-19). Available at: https:// www2.hse.ie/coronavirus/?gclid=EAlalQobChMI7ZeAz-WF6QIVzO3tCh2g8w9jEAAYA SAAEgLyBfD BwE\&gclsrc=aw.ds. Accessed 15th May, 2020.

13. Health Service Executive (Ireland). Mental health support and services during COVID-19. 2020; Available at: https://www.hse.ie/eng/services/list/4/mental-healthservices/connecting-for-life/news/supports-and-services-during-covid-19.html. Accessed 15th May, 2020.

14. Department for Business, Enterprise and Innovation. Supports for businesses impact by COVID-19. 2020; Available at: https://dbei.gov.ie/en/Publications/Publication-files/ Supports-for-businesses-impacted-by-COVID-19.pdf. Accessed 15th May, 2020. 